\title{
Double Vision: The Divided Self in Near-Death Experiences and Postmodernism
}

\author{
Raymond L. M. Lee, Ph.D. \\ Kuala Lumpur, Malaysia
}

\begin{abstract}
In Peter Novak's recent work (2003), he suggested the hypothesis that the human self is intrinsically bifurcated and separates into distinct components of consciousness at death. He referred to the near-death literature for evidence of this separation. His analysis of this literature implied that the after-death experience is not sequentially determined but is shaped simultaneously by different events corresponding to those components of consciousness. His proposal to reconcile those components addressed the need for selfintegration at death. However, proponents of postmodernism question the singularity of self-identity and propose the multiplicity of self-experience. Their challenge to the belief in a wholly integrated self brings into question the therapeutic value of recognizing self-division in death. If the self lacks a foundation, then it is fruitless to seek an illusory level of integration. Rather, self-division in death points to a more astute understanding of the emptiness of the self.
\end{abstract}

KEY WORDS: divided self; near-death experience; nothingness; postmodernism.

It is generally taken for granted that individuals have unitary selves. Indeed, the notion that people may possess multiple selves tends to be considered untenable or even pathological. Self-identity is premised on an unqualified belief in the manifold character of a person as rooted in a core or foundation of being. Without this core, selfidentity is considered inauthentic, false, or fragile. The romantic search for an unblemished self, free from the taint of social hypocrisies

Raymond L. M. Lee, Ph.D., is a retired Associate Professor of Anthropology and Sociology at the University of Malaya. Reprint requests should be addressed to Dr. Lee by e-mail at rlmlee@tm.net.my. 
and the vapid conventions of everyday life, can be regarded as the epitome of this belief in the foundation of being. To be free in this sense is to know one's foundation of being. This freedom is allegedly lost when the core of being is sacrificed to the chaos of multiplicity. It means that the self has become anchorless, adrift in an ocean whereby anything can come to determine its being. When being takes on a multiple character in which no foundation becomes possible or comes to represent a source of authenticity, a pathological state apparently sets in to distort the person's relationship with oneself and with others. Selfhood is then seen to be an unceasing struggle between multiple fragments of being, each attempting to lay claim to the dominion of the self.

The modern paradigm of the healthy individual rests on the assumption that all selves are naturally inclined to claim a pristine nucleus of being. When selves begin to create different levels of being that do not resonate with each other, they come to contradict this assumption and supposedly take on a distorted view of the world and all the objects within it. The well-known existential study of schizophrenia by the British psychiatrist, R. D. Laing, represents such a position. According to Laing (1965), the schizoid individual treats being as composed of at least two selves: an inner self that remains hidden or shut up and a false self that is constructed to deal with the actions of the outside world. Both selves remain at a distance, resulting in pathological tensions within the individual and between the individual and others. In extreme cases, schizophrenia occurs. These tensions imply that selfhood is fractured and lacks a core that governs authenticity. The inner self of a schizoid person cannot be ineluctably considered a foundation because it is described as vacuous and ontologically insecure. Schizophrenia is thus a disease of the divided self.

Yet this disease afflicts the modern world in general. Modernity represents a condition of rapid changes, ambiguity, and ambivalence despite advanced technological developments in mastering the natural and social environment. It is a condition that attempts to produce greater ontological security by rational means and instrumental control, but at the same time it is also vulnerable to its own systemic contradictions. The British sociologist Anthony Giddens (1991, p.167) described this situation most succinctly in terms of the deroutinizing potential inherent to modern routines. These routines allegedly provide ontological security but may come to be experienced as 
overwhelming or empty of meaning. Consequently, they may be challenged or disrupted to cause existential crises. In other words, modernity cannot guarantee ontological security because the very nature of modernity is schizophrenic. This paradox implies that the divided self is not necessarily the pathology of personality but of the whole modern system. The French poststructuralist writers Gilles Deleuze and Felix Guattari (1988) expressed this understanding of schizophrenia as a multiplicity of desires accelerated by modern capitalism that became encoded to create order as well as disorder. From their perspective, schizophrenia is not construed as individual pathology but as a motif of multiplicity in which the self cannot resist the diverse levels of being created by crisscrossing patterns of desire. The question of ontological security does not arise because the semblance of chaos in multiple desires addresses the modern state of being. In modern capitalist culture this tumult may seem threatening, but it is convergent with the expansive and exploitative nature of capitalism itself.

The concern with modernity and capitalism tends to give the impression that the divided self is a result of systemic forces rather than individual psychology. Consequently, the self is viewed as a byproduct and not its own being with autonomous experiences. However, shamanism suggests an alternative approach that attempts to treat the divided self as neither pathological nor an outcome of modern forces. As a mediator between this world and the realms beyond, the shaman is often considered someone with multiple selves in trance and spiritual performance. The shaman appears to possess a normal self but is also a vehicle for the expression of other selves. There is indeed a semblance of schizophrenia in shamanic behavior that some Western anthropologists have noted (Silverman, 1967), although other anthropologists have argued for a phenomenological rather than a diagnostic understanding of self-division in shamanism (Noll, 1983). Within the traditional framework of healing and spiritual sojourning in many pre-modern cultures, the notion of powerful thaumaturgy originating from a healer with multiple selves is not regarded as alien or abnormal. Rather, it can be seen as the recognition of the shaman's innate or acquired ability to manipulate forces in the spiritual and mundane worlds. The shaman himself may come to perceive self-division as necessary and its own form of spiritual empowerment. For example, Peters and Price-Williams (1980, p. 404) described the trance experiences of two Nepali shamans, 
one of whom was able to stand back and watch himself perform while the other experienced amnesia during trance and, when revived, was taken aback by the recorded events. This account of shamanism suggests that spiritual power may be intricately linked to self-division, and the pathological labeling of such power only functions to deny its expression.

Shamans generally work in cultural contexts in which people suspend disbelief in spirits and spirit possession. This phenomenon implies that the spiritual basis of self-division is not exclusive to shamans because ordinary people also share the belief that susceptibility to possession can result in the loss of an integrated self. Canadian anthropologist Michael Kenny (1981) asserted that in the proper context the experience of possession may be seen as unfortunate but not pathological. However, he argued that such contextual relevance tends to be denied to the understanding of the Western multiple personality syndrome, which is inexorably shaped by a culture-specific theory focused on the nature of self-integrity. Thus the multiple personality syndrome reflects less the idea that people may have multiple selves than the belief in the unstable foundation of the divided self. For him, it is the cultural and social contexts that nurture such a belief, "those things which establish the boundaries of the perceived world, the social definition of the unacceptable in thought and deed, and the vaporous outlines between what is self and what is not" (p. 354).

Indeed the boundaries of the perceived world have now undergone transformation to challenge the conventional belief in the nature of the integrated self. More space has been created to reinvent the self as a concatenation of selves without emphasizing the attribute of abnormality. The zeitgeist of this new space can be located in the efflorescence of New Age beliefs stressing the spiritual potentiality and freedom in humankind (Heelas, 1996). These beliefs offer a more liberal approach to understanding the inner nature of humankind as a dynamic arena of creative forces rather than a static core of socially determined characteristics. As an example, the inner revelations of near-death experiencers suggest a parallel to the spiritual discoveries of New Age seekers (Lee, 2003). The New Age movement itself cannot be regarded as the original basis for the redefinition of the divided self, but it can be seen as an emergent social and spiritual alternative that is re-addressing the age-old question concerning the locus of personal experience. It is an alternative that expresses dissatisfaction with a 
worldview tied to the empiricism of scientific control and the influence of discrete objectivity. New Age beliefs are focused on the meaning and pursuit of inner spirituality and are counter-cultural in the sense of disputing conventional notions of selfhood. For many New Age followers the self is more magical than is conventionally thought and is therefore open to many possibilities of being. These possibilities suggest that personal experience is not merely dependent on the structural actions of the external world. Rather, the inner world of each individual offers greater scope in accessing the meaning of being and the varying levels of consciousness that shape and reshape selfperception.

The New Age movement represents changes in the wider social context that have been described in various ways as postmodern, and the word postmodernism has entered the social lexicon to suggest a greater receptivity to the many possibilities of being. In this context, challenges to the conventional unitary self may not be considered quaint but necessary in order to adumbrate the arbitrariness of selfdefinitions. My intention here is to sketch out the postmodern context in which conceptions of selfhood have been redrawn in order to argue that the redefinition of self-division is premised on new perceptions focusing on the plurality of the self. It is this watershed of selftransformation that has also affected the meaning of self-division in death, particularly the role of self-perception in near-death experiences (NDEs). I will address the problem of self-division in NDEs following the discussion on postmodernism and self-plurality.

\section{The Self in Postmodernism}

Postmodernism was a fin de siècle phenomenon of the $20^{\text {th }}$ century and can be construed as a cumulative effect of the social crises, counter-cultural movements, and political rebellions of the postwar years in the West, more specifically the 1960s. Nurtured by a long tradition of philosophical skepticism, postmodernism came to represent a disruption of modern reason for turning the entire project of modernity on its head. This disruption did not occur in a social or cultural vacuum. The American literary theorist Frederic Jameson (1991) conceived of postmodernism as a logical outcome of late capitalism, a period of socioeconomic development characterized by intense fragmentation, pluralism, and a plethora of choices in consumer society. As he saw it, the rise of postmodernism could not 
be divorced from the growth of a world-market system that bred pluralism. Within this kaleidoscope of consumer-driven expressions, postmodernism came to be regarded as a new way of refashioning the world in the image of what was once considered unacceptable. The French philosopher Jean-Francois Lyotard (1984) referred to this redefinition of the world as the death of meta- or grand narratives. Sweeping assumptions of life in the modern world were now to be swept away to make way for other narratives once relegated to the margins. In this vein, the Polish sociologist Zygmunt Bauman (1992) addressed postmodernism as a reenchantment of the world, "as restoring to the world what modernity, presumptuously, had taken away" (p. x).

One outcome of this reenchantment of the world pertains to the increasing diversity that cuts across all boundaries. American psychologist Kenneth Gergen (1991) related this diversity to "the onset of a multiphrenic condition, in which one begins to experience the vertigo of unlimited multiplicity" (p. 49). Interestingly, Gergen had chosen to cast postmodernism in the light of this curious word, multiphrenic: a word that depicts simultaneously the process of multiplication and arbitrariness of subjective experiences. A multiphrenic condition breaks down any attempt to constitute and maintain a core of being. In Gergen's view, we come to take on partial identities through mass communication and consumption. These partial identities suggest that we can assume a variety of selves without the necessity of privileging one over the others. Even Laing's concept of the inner self may not be relevant in this situation that levels all aspects of being to a patchwork of self-presentations. There is no depth of being or even a quest for one because "we get fragments or 'fractals' of reason and an anonymous individual submitted to the play of structure, power or narrativity" (Løvlie, 1992, p. 123).

Thus in postmodernism all individuals, sane or insane, are reduced to fleeting shadows of selves that cannot or do not possess any inkling of inner authenticity. All self-identities are derived from the intermixing of images in society saturated with electronic media and signs of consumption. These identities are mere copies of images that can be likened to consumer items on supermarket shelves. Each item is a copy of a collection of items on a particular shelf. Although items on different shelves are not the same, they are not distinguished in terms of authenticity. All items have utilitarian value, and in that sense they are all individually authentic. A postmodern self is 
therefore a reproduced copy of other selves that does not find the need to make hard and fast distinctions between inner and outer levels of being. Unlike the schizoid individual described by Laing, the postmodern self sees no reason to cocoon the inner from the outer or "false" self because both are equally considered authentic. Hence, schizophrenia may be regarded as an illusory outcome of the belief in the reality of an inner being. The multiphrenic condition provides an ideal occasion for the removal of this illusion because immersion in unlimited multiplicity allows a person to flit between numerous identities without necessary reference to a core of being. Each identity becomes its own momentary reality and finds no compulsion for locating a core because multiplicity facilitates fluidity. It is this fluid situation that dissolves the perception of inner and outer being but enhances the experience of mobility between multiple roles and roleperformances. These roles and role-performances form the basis of all subjective relationships and contribute to the sense of arbitrariness pervading the choice of identities.

Two significant themes pervade the postmodern approach to the self: to treat all selves as depthless and to normalize the experience of self-plurality. First, the self is perceived to be depthless in the sense that the need to seek a core of being does not arise. The quintessential self with an intact inner being is considered mythic because such a being is not plausible in the light of the myriad experiences encountered in an environment of multiplicity. Every situation in this environment requires a rapid or spontaneous change of roles and role-performances, implying that it is most impractical for an individual to continuously hinge this change to a center or core as if central headquarters needs to know and monitor all one's movements. Lack of depth in the postmodern self represents a pragmatic strategy in dealing with multiplicity, and depthless identities allow quick and skilful maneuvers for adapting to all kinds of situations. By eliminating the need for a foundation of being, postmodernism has introduced a new way of speaking about self-division as a function of reenchantment. It implies that reenchantment instills an apparently greater sense of freedom through the experience of self-division unlikely to be attained under the management of an inner center. In that sense, reenchantment seeks to undermine the meaning of selfintegrity in modernity.

Second, the self-division that results in a concatenation of selves may no longer be construed as psychologically abnormal because it is 
arguably a social and cultural response to the multiphrenic condition. If this condition has become the norm in late capitalist society, it means that individuals are not simply behaving irrationally when they seem to have multiple selves. Rather, they are compelled to regard rapid role switching and shifting role-performances as more meaningful than preserving a core of being. They may even come to see the strategic implications of self-division and self-plurality in the drive toward social achievement. Only by adopting many masks and not holding on to an inner being can a person adapt to the multiphrenic condition. Thus it is the adaptive function of self-division and self-plurality in postmodern society that makes problematic the meaning of abnormality attributed to the multiple personality. Such a personality cannot be seen in blanket terms as odd given a situation that promotes crisscrossing patterns of desires. In this regard, shamanic performances that feature multiple role changes may be considered parallel to self-plurality in postmodernism. Not only are such performances remotely pathological, but they also suggest the necessity of self-plurality in healing rituals and spiritual interaction.

This reinterpretation of the multiple personality suggests the crystallization of an alternative viewpoint on self-ontology already evident in earlier critiques of mental health and pathology that attempted to disparage the conventional standards of abnormality (Rosen, 1969; Szasz, 1961). It was not the intention of critics to advocate a criterion of normalcy for the apparent Jekyll-and-Hyde nature of the human self. Rather, they were arguing for a contextual understanding that took into account the way self-plurality was perceived as deviant from the modern definition of the unitary self. The emergence of postmodernism took this understanding a step further to give self-plurality a conceptual autonomy to emphasize its own reality as distinct from one that repeatedly disparaged selffragmentation. To no longer assume that the self was irrevocably integrated was not merely a radical departure from the normative measures of psychological stability. It also shifted the lenses of selfdiscovery from the so-called objectivity of the scientific observer to the experiential perspectives of the subjects themselves. Although the subjective experiences of self-plurality were either considered symptomatic of psychological disturbance by medical professionals or preserved in the private domain by individuals, they have now been redefined as important data for research into human consciousness. This change of perspective suggests an implicit dissatisfaction with 
the idea that human consciousness and selves are inherently conjoined and well integrated. It also suggests a nostalgic turn in consciousness studies that attempts to seek answers to the enigma of self-plurality by referring to the beliefs of ancient civilizations. This return to ancient beliefs for an understanding of self-plurality is exemplified by the "binary soul doctrine" proposed by Peter Novak, which I next discuss.

\section{The Binary Soul Doctrine and Near-Death}

Peter Novak (2002, 2003) addressed the complexities of the human self and consciousness as the interplay between partial identities that can be attributed to left and right brain functions. He used the popular term soul to refer to the constitution of the self and self-consciousness - a convenient term for describing the spectrum of being that possibly survives physical death. It is this being with its individual memories and consciousness that provides a sense of selfhood that splits up in death. Citing a wide array of data from different historical periods, he argued that there is consensus on the dual nature of the human self that seemingly cannot be held together upon the demise of the physical body. Many ancient civilizations such as those in Egypt, China, India, Greece, Persia, and Meso-America allegedly subscribed to the belief that following death, one aspect of the self went on to reincarnate while the other aspect became trapped in the netherworld. This belief constituted what Novak (2003, p. 11) called Binary Soul Doctrine cultures around the world. In other words, humans in the past had an understanding of the divided self, but this knowledge was lost or repressed until recent times. Recovering this knowledge could have been partly inspired by work on the bicameral mind (Jaynes, 1976) and by split brain research (Springer \& Deutsch, 1985).

Novak (2003, p.164) came to the conclusion that the self or soul is intrinsically a bifurcated entity but perceived by most people as if it is a whole being. Just as each eye produces only two-dimensional images but together constitutes a three-dimensional vision, the mind seems to take the dualistic self as one. Such perception is functional to the extent that it creates a sense of order in the context of interaction with other individuals. But at death this perception is undermined by a seemingly natural separation of the self into two spheres of experience: one part subjective and emotional and the other rational 
and objective. As he put it, "If people split into pieces at death, it can only be because they were already fractured long before they died, but never noticed it before" (p. 204). He attributed this lack of awareness of self-division to the repression of the unconscious. This attribution suggests that all forms of unconscious expressions representing another self are immediately blotted out, so that the individual only refers to one's own rational side as truly representing a specific selfidentity. Blotting out the unconscious produces a cognitive illusion that masks self-division and gives rise to a semblance of selfcontinuity (p. 158).

To substantiate the importance of the Binary Soul Doctrine, Novak (2003) drew from many sources of empirical data such as past life regression, paranormal phenomena, and, most compellingly, the large literature on NDEs. This literature rarely focuses on testimonies that suggest self-division. NDEs have generally been treated as holistic experiences as if the returnees' narratives represent unbroken sequences of events in an afterlife travelogue. Novak's approach was not to dispute the validity of these experiences but to reanalyze them for possible evidence of self-division that the near-death experiencers (NDErs) themselves could not have known. The assumption here is that NDErs, like most people, do not personally recognize their split identities and therefore are in no way sensitive to the subtleties of multiple perceptions when out of the body. However, their accounts may contain contradictions or inconsistencies that can be taken as indications pointing to a lack of holistic perception. In short, their narratives provide support for the Binary Soul Doctrine even though they may not be fully aware of it.

The underlying methodology was to reinterpret the two-stage encounter with darkness and light as a simultaneous rather than sequential experience. Novak (2003, p.160) offered the argument that normal temporal experiences are suspended in NDEs, and so it is not possible to describe events in a before-and-after fashion. NDErs tend to adhere to this type of description because of a built-in cognitive illusion that calibrates their perception in tandem with the belief in self-integrity. Because most NDErs regard their identities as intact wholes, they are more likely to interpret their experiences with the dark void and realm of light as sequential events. To address the simultaneity of these events would only contradict the belief in selfintegrity, as perception (and thus the self) has to be split in order to experience darkness and light at the same instant. 
NDErs often describe the dark stage as an unbounded and featureless void or tunnel where they experience extraordinary tranquility and absolute detachment. Not only do they feel extremely alert but also highly distant and analytical as if the left-brain was functioning on its own at full capacity. They experience the light stage as the inverse of the dark stage: NDErs encounter "intense surges of emotion, ... are now subjective, involved in and affected by everything going on around them ... [and] feel an intimate connection to the entire universe" (Novak, 2003, p. 54). This is the stage that Novak considered the most researched aspect of NDEs over the last quarter century. It appears to be the most dynamic and intense level of NDE reports, arguably representing the unconscious half of the self that gains full expression in a near-death situation. These reports belie, in Novak's opinion, the simultaneous occurrence of both stages, because most NDErs still routinely interpret their experiences as occurring in real time. They actually fail to perceive these experiences as reflecting a split in the self. However, Novak (pp. 83-87) did include many accounts provided by NDErs who claimed to recall experiences of selfdivision. These individuals reported that they saw their other selves or doubles during the NDE.

In Novak's view (2003, p. 88), failure to prevent self-division at death constituted the main concern of many ancient peoples such as the Egyptians and Chinese. However, the problem of self-division does not seem to be central to many NDErs' interpretation of their experiences. He pointed out that even NDE researchers like Kenneth Ring construed some experiences in NDEs as reflecting the contents of a false self. Ring interpreted post-NDE changes in personality as the falling away of a false self and the emergence of a more authentic and altruistic self (Ring \& Valarino, 2000, p. 52). Distinguishing between these two selves seems to emphasize the dominance of one over the other rather than an actual integration of both. In this case, it appears that the conscious and rational aspect comes to exert greater influence after the NDE. Hence, to assume the arising of the unconscious in NDEs as equivalent to the assertions of an inauthentic self represented for Novak a pro-division approach that belittles the putatively emotive and feminine aspects of all selves. NDEs are considered vital experiences that illuminate the multifaceted nature of the self, which require integration as the means of preserving selfidentity. Thus, he acknowledged the mental integrity of NDErs who have confronted and reconciled all fragments of the self (p. 241). 
The Binary Soul Doctrine may be considered an attempt to address the existential ambiguities of the modern self. It adumbrates the concern with how self-coherence can be maintained by overcoming all its conflicting aspects. Subscription to the belief that self-division will occur at death provides proponents of the Binary Soul Doctrine with the caveat of impending self-fragmentation. For Novak (2003, p. 225 ff), this concern with self-fragmentation implied developing techniques for "forging a self that won't shatter at death." These are techniques for unifying the various aspects of the self, such as maintaining unlimited interaction between the conscious and unconscious. This unification can happen during the life review in the NDE because unconscious memories are reintegrated into the conscious mind and healing takes place (p. 237). Healing the rift between the conscious and unconscious is considered the key to preserving selfidentity beyond death. It is based on the modernist assumption that wholeness of the self cannot be compromised and that self-repression leads to pathology. By not recognizing the "patchwork of many people" trapped in the unconscious, full integration cannot be achieved and "we remain divided, strangers to ourselves" (p. 241).

The Binary Soul Doctrine essentially addresses the failure of the self to recognize its own fractured nature. In terms of the modern paradigm of the healthy individual, self-division or self-plurality is regarded as a threat to self-integrity, because no individual is deemed to be functioning properly if various aspects of the self are not reconciled or therapeutically realigned. The self can attain ontological security only if its integrity is not compromised. Proponents of the Binary Soul Doctrine are, therefore, arguing for a more effective approach to acquiring ontological security by raising awareness of the propensity toward self-division that could irreversibly jeopardize selfidentity, particularly at the moment of death. In a sense, their proposal to fortify self-identity under the threat of fragmentation at death converges with the sociological concern of partial self-identities developing under the multiphrenic condition of postmodernism. This condition does not explicitly concern the problem of human mortality but stands the modern paradigm of the healthy individual on its head by disprivileging the significance of ontological security. For many postmodernists, fragmented selves are not necessarily selves under threat. On the contrary, recognition of partial self-identities is defined as a passport to greater freedom because there is no core or foundational identity to protect or to be used as an exemplar. Self- 
plurality is celebrated as the unfixing of static identities inured to the idea of self-integrity and ontological security. It is this self-plurality that undermines all notions of authenticity by emphasizing the arbitrariness and relativity of all fragments rather than the stoic solidity of an apparently unified self.

Thus, the Binary Soul Doctrine and postmodernism address selfdivision as central to self-understanding, with the former suggesting the necessity to integrate the conscious and unconscious aspects of the self and the latter the letting go of a unitary self. Proponents of the Binary Soul Doctrine take the NDE as an important instance of selfdivision. They treat the dark and light experiences as well as the encounter with doubles as signaling the existence of fragmented selves that require reconciliation. It is not entirely clear how this reconciliation can be achieved during an NDE, although Novak himself seemed to believe that some NDErs emerge from their experiences as more integrated individuals. The bottom line is that the NDE represents an ideal occasion for self-healing and self-reflection so as to recharge the quest for a more perfect self-identity.

As if to reverse this quest, the anti-foundational approach in postmodernism suggests a tendency toward decentering or dismantling the coherence of all self-identities. For most postmodernists, not recognizing the "patchwork of many people in the unconscious" is unlikely to be addressed as an ontological problem. Rather, this patchwork is to be left alone because self-division is not interpreted as a threat to an illusory integrated self. The multiphrenic condition of postmodernism not only breeds self-plurality but also leads to the recognition of arbitrariness as a source of creativity. Taken in this context, efforts at self-integration may ultimately be seen as a form of self-deception that deprives the individual of extensive creativity in navigating through worlds of diversity. If some of these worlds include those traversed by the NDEr, then finding the means to heal and fuse the divided self would serve only to inhibit the creativity needed to confront the myriad mysteries awaiting the NDEr.

In this sense, postmodernism seems to offer a more pragmatic approach to the exploration of afterlife experiences than the integrative principle suggested by the Binary Soul Doctrine. I do not mean by this statement that a postmodern choice is preferable for adapting to afterlife conditions such as those NDErs report. Rather, postmodernism does not emphasize the need for self-integration before and after death and so adopts a more open approach to the vicissitudes 
of this life and the next. On the other hand, the integrative principle suggested by the Binary Soul Doctrine focuses on the preservation of a recognized self-identity. Clinging to this identity in uncharted afterlife conditions may indeed reinforce experiencers' idea that they have not lost the familiar props of a previous existence and can provide an anchor for re-assessing the meaning of "life after life." However, as returnees to this life, NDErs can claim only to glimpse the afterlife and cannot determine the effectiveness of maintaining a reconstituted self-identity beyond the present life. In short, they cannot ascertain the prescriptions of the Binary Soul Doctrine.

\section{Self and Nothingness}

Basically, postmodernism provides an anti-foundational perspective on self-identity that does not explicitly have any bearing on the meaning of the NDE. It reverses the disparagement against selfdivision by redefining the inconsistencies of the self as a new form of playfulness or self-plurality that cannot be confined to an allembracing center. This playfulness suggests that the reality of the self is relational because it is contingent on the arbitrariness of all its different aspects. It implies that the self cannot attain the status of an autonomous whole and that if such a claim is made, it is merely illusory. If playfulness points to a lack of essence, then self-plurality is merely an interaction of shadows without the need to posit a ground of ontological security. In other words, the self realizes its various roles in life do not necessarily add up to an intrinsic foundation of being. For this reason, postmodernism has been criticized as promoting nihilism because its emphasis on relational differences tends to open the way to the argument for nothingness. Postmodernists are apt to consider futile the need to discover a core of being or to distinguish between authentic and false selves. All selves exist only on the surface, and there is nothing beneath this surface. Thus, one can conventionally speak of self-presence within the context of others, but to read a deeper meaning into this presence is considered a fruitless flight of the imagination.

Yet it is possible to see that this anti-foundational perspective is not just a postmodern parody of the self. Playfulness in postmodern parlance discloses a play on nothingness from which arises the meaning of presence as if the tolerance of emptiness has been exceeded. Presence is the attempt to delineate identity from 
nothingness and to fashion it into diversity. It suggests a form-seeking playfulness that has been repeatedly described by NDErs in their encounters with darkness and light. Typically NDErs refer to the dark stage as a journey through a void like facing an abyss with nothing in view or for support. The darkness itself is emblematic of nothingness punctured only by the NDEr's presence. The NDEr is alone in darkness, an alienated presence hurtling toward a point of light that grows larger as if to absorb it. Most NDErs do not seem to express the wish to remain in darkness, that is, to blend into the darkness and to lose the sense of presence. Rather, they are drawn into the allembracing light to experience its radiance and currents of compassion. This is the veritable voyage in self-knowing: to lose the self in darkness and to recover it in the light. The light stage is a stage of interaction, the occasion for coming into the presence of others such as deceased friends and relatives, spirit guides, and beings of light. Selfidentity is restored because lack of direction in the dark is replaced by the communicative action of other identities in the light. The concrete form of this self-identity is regained when the NDEr is "sent back" into one's physical body. Thus, the play of darkness and light in the NDE is suggestive not only of the inevitable brush with nothingness but also of the postmodern disclosure on the problem of self-inherence. Most NDErs are familiar with the former but not necessarily with the latter.

Proponents of the Binary Soul Doctrine are more likely to take the play of darkness and light as a scenario for the separation of consciousness than as a metaphor for the emptiness of the self. Darkness is associated with the experience of detached calm and undisturbed objectivity, a kind of dispassionate floating in unbounded space. Light represents the stage of increased emotional involvement in a newfound context of brilliant forms and profound meanings. Novak (2003, pp. 55 and 60) identified darkness as underlying the sense of complete release concomitant with the working of the conscious mind and light as the expression of infinite joy coming from the depths of the unconscious mind. These opposing sets of experiences in the NDE were interpreted as discrete operations of the bifurcated self, which is not aware of its own division but perceives the play of darkness and light as a sequential flow of events.

Interestingly enough, Novak (2003, p. 54) made a brief reference to The Tibetan Book of the Dead as part of his comparative review of the literature on the afterlife. This book has been translated thrice into 
English $(1960 ; 1987 ; 1994)$ and represents a cornerstone of Tibetan Buddhist discourse on the meaning of death and the wheel of life. Central to this discourse is the Tibetan idea of bardo, the in-between states that all beings experience in this life and the afterlife. Bardo includes the dark and light stages of the NDE. Novak interpreted the Tibetans as giving more importance to the bardo of darkness than that of light because they view the former as the "clear light of the void" or ultimate reality. On the other hand, he argued that NDE researchers tend to emphasize the light stage as more real. It is ironic that Novak (2003) addressed the Tibetan concern with darkness as the moment of pure self-realization - "the only Being that has ever existed" (p. 54) in order to illustrate a distinction between bardo states that possibly corresponds to the splitting of the self in death. If this concern with darkness is described metaphorically as the clear light of the void, then it is not merely an immediate experience of darkness but a penetrating insight into the nature of the self. The light in this sense is not physical or mystical but a metaphor for the mind realizing the self as singularly free, unhindered by objects and relations, transparent to itself, and without the need to account for itself and others. It suggests an ideal moment of realizing without hesitation the emptiness of the self before it is plunged again into the bright context of self-renewal in the presence of other beings. But Novak interpreted the darkness as the profundity of the conscious mind acting on the self without any input from the unconscious half, thereby heightening its powers of objective awareness. He explained the experience of nothingness as a function of the conscious mind alienated from its unconscious aspect rather than as an epiphany of self-realization. Thus, the likely convergence between his interpretation of bardo of darkness as a state of self-revelation and the postmodern refutation of self-ontology is missed because the concern with self-division leads directly to the attempt to seek a solution for healing the split rather than realizing the emptiness of the self.

The Binary Soul Doctrine is therefore a product of the modern concern with self-integrity and threats to that integrity. From the modern perspective, the self constitutes a center of being that encounters its own presence and the presence of other beings and objects. It develops an awareness of lived experiences in order to perpetuate an identity that has continuity. These are significant experiences that the emerging identity is always able to reflect on, in order to reify its own presence in the context of 
others. Maintenance and protection of this identity are foremost in the minds of proponents of the Binary Soul Doctrine because they fear the divided self as being unable to recover its identity and perpetuate a unified presence. Because Binary Soul Doctrine interpretations of the NDE phenomenon are made within the modern perspective, the focus on the dark and light stages in the NDE is inadvertently linked to a view that suggests the urgency of preserving self-identity. Thus, it is not the NDE per se that is construed as a threat to the self but the failure to address the meaning of darkness and light as symptomatic of self-division in death. Within this perspective, NDErs can be made aware of this potential threat to their identities and possibly take precautionary measures to reconcile the alleged bifurcation. As it can be plausibly assumed that most NDErs (in the West at least) maintain a modern outlook, development of this awareness can be taken to imply the continuing quest to fortify the self as it confronts the meaning of its mortality. Could it be possible, then, that if NDErs were to adopt a postmodern perspective, they would interpret differently the experience of darkness and light?

The dark tunnel and emergence into light have become the classical motif of NDEs. It can be considered a motif molded by the modern self in traversing the after-death realms as if propelled by a sequential motion of time vital to its sense of an integrated identity. In almost all NDE narratives, this motif is always expressed as a reassurance of one's self-identity. The NDEr does not seem to lose one's sense of self first in darkness and then in light. There is no hint of an absence of self in these experiences. Rather, the NDEr's self-identity is reinforced by the instruction to return to the physical form. On the other hand, Novak disputed the meaning of time in the experience of darkness and light, that is, that this is not a sequential but a simultaneous experience. In a sense, he offered a postmodern perspective to this motif by problematizing time as a determinant of events. In postmodernism, time is compressed by space as if all events occur simultaneously. In an NDE time may be experienced as standing still (Lee, 2004). Thus, simultaneity connotes a tendency toward selfdivision that accentuates the postmodern refrain on the impossibility of an integrated self. Yet Novak attempted to represent self-division as inimical to self-identity rather than following through the postmodern argument that self-division points to the illusion of self-identity. If this argument is pursued, it is possible to view the dark and light stages in 
the NDE as existential alternatives or bardo electives that address the reality of the self.

The dark stage receives scant attention because it is associated with the sense of nothingness and the lack of human continuity. NDErs often describe it as the zone of ultimate alienation where the self experiences the state of being alone. From the postmodern perspective, aloneness can be interpreted as having no self that is made real because there is nothing for it to relate to. The self $i s$ the existential vacuum. Hence it is not the darkness that is real or threatening, but the realization that there is no beyond and that aloneness is all there is. Darkness is therefore a metaphorical translation of being alone, the pristine presence of one and the transparency of all selves. There seems to be no record in the NDE literature of any NDEr who merely remained in the dark tunnel, which is often taken as a type of conduit to the zone of light. Is this because NDErs regard darkness as a threat to their self-identities and therefore feel compelled to move toward the light? Because darkness connotes meaninglessness, NDErs may feel driven by the need to seek meaning in the light where relations can be established and renewed. In other words, NDErs can possibly decide to stay in darkness if they do not perceive it as an annihilator of selfidentity. But NDErs typically move on to the light and return with transformed selves to the human world of myriad meanings, suggesting an affinity between near-death and the modern quest for self-identity. Even the title of Ring's book Lessons from the Light (2000) gave the impression of the profound changes in self-identity as a result of the light, not dark, experiences. Lessons from the dark would pose the problem of self-meaning and lack of context in the formation of self-identity. Such lessons may cast a different perspective on the nature of the self and bring it closer to the purview of postmodernism. They may reverse the quest for certainty of the self into cogitation on the fragility and emptiness of the self.

\section{Conclusion}

From the modern perspective, no self can be thought of as lacking in a core of being that determines individual authenticity. Modern selfidentity is constructed on the basis of knowing this authenticity as crucial to the development of all social relationships. When this authenticity is challenged or made problematic, self-identity comes to be perceived as possibly pathological or mirage-like in expression. 
Thus the alleged appearance of the multiple personality is considered a threat to the modern definition of the healthy individual with a purportedly intact self-identity. Yet shamans who display multiple selves under possession are not generally treated as though they need psychiatric therapy. They represent another cultural viewpoint that does not consistently disparage the manifestation of self-plurality. Such a viewpoint has now converged with the postmodern discourse on self-fragmentation. If the self is not as unified as it seems in postmodern culture, then what precisely is its nature, or is it even possible to speak of a nature?

Postmodernism raises the possibility that the self is only a construction derived from the relativity of language and socioeconomic conditions. There is no inner or outer self but a collection of selves that is conventionally identified as an individual identity. Selves seem to become chaotic without this conventionality but are actually a play of different roles on the surface. Beneath this surface there is nothing, an emptiness that apparently threatens the pursuit of self-meaning. Is this emptiness the dark void that many NDErs have talked about in their experiences out of the physical body? Generally NDErs do not lose their sense of self-identity when they traverse the dark tunnel or the unbounded void toward the zone of light. If NDErs adhere to the modern perspective that they possess unitary selves, then it is likely that they would not interpret the darkness and light as meaningless events but as significant experiences leading to the reinforcement of their identities. As Novak argued, these experiences are interpreted sequentially because temporal interpretations do not threaten the sense of self-identity. If darkness and light are to be perceived simultaneously, it will imply that there is no unitary self to process sequential events and that the self can be fragmented to experience both events at the same instant. It also suggests that the simultaneous experiences of darkness and light represent specific choices that can result in the realization of "selflessness" in the void or the continuation of the self in the light. Most NDErs do not choose to stay in the dark tunnel and so experience only an ephemeral sense of "selflessness." There is no record in the NDE literature detailing prolonged sojourns in the dark zone and their effects on selfperceptions. Is it plausible, then, to suggest the experience of darkness as having some equivalency to the postmodern critique of the self as ontologically empty? That is to say, darkness itself is the realization of "selflessness." 
It is no coincidence that NDE research expanded alongside postmodern debates on the nature of the self. Both are concerned with the problem of human self-identity in life as well as in death. NDE research is providing us with ample evidence to suggest that the self does not perish at the moment the physical body ceases to function. The self moves on to other levels of consciousness after the demise of the physical body. But this research is also indicating that these levels of consciousness do not necessarily correspond to the conventional definition of unitary self that people take for granted in their modern lives. On the other hand, postmodernism is not explicitly concerned with the issue of death and dying, but its problematization of self-identity aligns it with the question of postmortem self-division raised in NDE research. The convergence of these two fields of inquiry into the nature of the self opens up new opportunities for further research into the context of perception and interpretation of the many levels of consciousness encountered beyond the confines of the physical dimension. It could also be seen as creating new openings into other areas of inquiry dealing with the meaning of the self in meditation and the quest for enlightenment. In short, the problem of the divided self as addressed by Peter Novak is not just a prescription for self-healing but a catalyst for transforming the fragility of the self into a more profound understanding of self-inventiveness.

\section{References}

Bauman, Z. (1992). Intimations of postmodernity. New York, NY: Routledge.

Deleuze, G., \& Guattari, F. (1988). A thousand plateaus: Capitalism and schizophrenia. Minneapolis, MN: University of Minnesota Press.

Gergen, K. J. (1991). The saturated self: Dilemmas of identity in contemporary society. New York, NY: Basic Books.

Giddens, A. (1991). Modernity and self-identity: Self and society in the late modern age. Stanford, CA: Stanford University Press.

Heelas, P. (1996). The New Age movement: The celebration of the self and the sacralization of modernity. Malden, MA: Blackwell.

Jameson, F. (1991). Postmodernism or the cultural logic of late capitalism. Durham, NC: Duke University Press.

Jaynes, J. (1976). The origin of consciousness in the breakdown of the bicameral mind. Boston, MA: Houghton Mifflin.

Kenny, M. G. (1981). Multiple personality and spirit possession. Psychiatry, 44, 337-358.

Laing, R. D. (1965). The divided self: An existential study in sanity and madness. Baltimore, MD: Penguin Books.

Lee, R. L. M. (2003). The reenchantment of death: Near-death, death awareness, and the New Age. Journal of Near-Death Studies, 22, 117-131.

Lee, R. L. M. (2004). The deconstruction of death: Postmodernism and near-death. Journal of Near-Death Studies, 22, 179-194. 
Løvlie, L. (1992). Postmodernism and subjectivity. In S. Kvale (Ed.), Psychology and postmodernism (pp. 119-134). Thousand Oaks, CA: Sage.

Lyotard, J-F. (1984). The postmodern condition: A report on knowledge. Minneapolis, MN: University of Minnesota Press.

Noll, R. (1983). Shamanism and schizophrenia: A state specific approach to the 'schizophrenia metaphor' of shamanic states. American Ethnologist, 10, 443-461.

Novak, P. (2002). Division of the self: Life after death and the binary soul doctrine. Journal of Near-Death Studies, 20, 143-189.

Novak, P. (2003). The lost secret of death: Our divided souls and the afterlife. Charlottesville, VA: Hampton Roads.

Peters, L. G., \& Price-Williams, D. (1980). Towards an experiential analysis of shamanism. American Ethnologist, 7, 397-416.

Ring, K., \& Valarino, E. E. (2000). Lessons from the light: What we can learn from the near-death experience. New York, NY: Insight/Plenum.

Rosen, G. (1969). Madness in society: Chapters in the historical sociology of mental illness. New York, NY: Harper Torchbooks.

Silverman, J. (1967). Shamanism and acute schizophrenia. American Anthropologist, 69, $21-31$.

Springer, S. P., \& Deutsch, G. (1985). Left brain, right brain. New York, NY: Freeman.

Szasz, T. S. (1961). The myth of mental illness. New York, NY: Harper and Row.

The Tibetan book of the dead. (1960). (W. A. Evans-Wentz, Trans). New York, NY: Oxford University Press.

The Tibetan book of the dead. (1987). (F. Fremantle \& C. Trungpa, Trans.). Boston, MA: Shambhala.

The Tibetan book of the dead. (1994). (R. A. F. Thurman, Trans.). New York: Bantam Books. 